\title{
Hipertensão renovascular na arterite de Takayasu: um relato de caso
}

\author{
Maria Julia de Aro Braz ${ }^{1}$, Leonardo Ervolino Corbi', \\ Luiz Aparecido Bortolotto ${ }^{2}$, Dante Marcelo Antigas Giorgi ${ }^{2}$
}

Braz MJA, Corbi LE, Bortolotto LA, Giorgi DMA. Hipertensão renovascular na arterite de Takayasu: um relato de caso. Rev Med (São Paulo). 2015 jan.-mar.;94(1):61-2.

\section{INTRODUÇÃO}

Arterite de Takayasu é uma doença inflamatória crônica, de etiologia pouco conhecida, que acomete mais frequentemente mulheres jovens, na vigésima ou trigésima décadas de vida, sendo mais prevalente no Japão, Sudeste Asiático, Índia e México. A doença afeta principalmente aorta, seus maiores ramos e artérias pulmonares, ocasionando estenose, oclusão e, menos frequentemente, dilatação e formação de aneurismas. $\mathrm{O}$ envolvimento de artérias renais é o mais comum nos casos em que se observa acometimento de artérias viscerais, sendo encontrado em 24 a $68 \%$ deles. Estenose de artéria renal gera hipoperfusão renal, ativação do sistema renina-angiotensina-aldosterona e retenção de sódio, modificando débito cardíaco e resistência vascular periférica. A consequente elevação dos níveis pressóricos caracteriza a hipertensão renovascular, que ocorre quando a estenose da artéria é superior a $70 \%$, sendo uma das causas mais comuns de hipertensão secundária, sobretudo em jovens. O manejo do paciente com arterite de Takayasu inclui medidas farmacológicas para controle pressórico e terapêutica intervencionista por tratamento percutâneo ou revascularização cirúrgica do território em isquemia. Será descrito o caso de um paciente com hipertensão de difícil controle por estenose de artéria renal, decorrente de arterite de Takayasu, submetido a tratamento percutâneo.

\section{OBJETIVOS}

Relatar um caso de arterite de Takayasu em paciente jovem do sexo masculino;

Destacar tratamento percutâneo, por angioplastia e implante de stent, frente à cirurgia de revascularização, realizada na maioria dos casos;

Demonstrar a importância da investigação, diagnóstico e tratamento corretos para boa evolução do paciente.

\section{RELATO DE CASO}

Paciente masculino, 26 anos, pardo, tabagista (20 maços-ano), sem diagnóstico de dislipidemia, previamente hígido, apresentou náuseas, febre e cefaleia intensa que o levaram a procurar atendimento, sendo diagnosticada hipertensão arterial. Iniciou uso de medicações antihipertensivas, sem melhora significativa dos sintomas. Seis meses depois, apresentou hiperemia conjuntival, com diagnóstico de uveíte em olho direito. Nessa ocasião, realizou exames de investigação do quadro oftalmológico associado à hipertensão. Monitorização ambulatorial da pressão arterial revelou média de 24 horas de 144x83 $\mathrm{mmHg}$, em uso de medicações anti-hipertensivas. Exames laboratoriais revelaram atividade inflamatória presente (VHS e PCR elevados) e reação de Mantoux fortemente

$1^{\circ}$ lugar Prêmio Painéis - Área Relato de Caso no 33 COMU - Congresso Médico Universitário da FMUSP, SP, 31 de out. a 02 de nov. de 2014.

1. Acadêmicos de Medicina da Faculdade de Medicina da Universidade de São Paulo.

2. Orientadores, Faculdade de Medicina da Universidade de São Paulo. 
positiva. Angiorressonância e angiotomografia de aorta abdominal mostraram alterações, incluindo artéria renal esquerda com estenose grave (70\%). Foi feito diagnóstico de arterite de Takayasu. Iniciado tratamento com prednisona associada a metotrexato. Permanecida a baixa atividade inflamatória (PCR e VHS reduzidos), foi indicado tratamento intervencionista. $\mathrm{Na}$ admissão, paciente apresentava pulsos simétricos e palpáveis, frequência cardíaca de $80 \mathrm{bpm}$ e pressão arterial, aferida com paciente sentado, de $140 \times 90 \mathrm{mmHg}$ em membro superior direito e 160x90 em membro superior esquerdo.
Presença de sopros carotídeo e abdominal audível em região supraumbilical esquerda. Em uso de anlodipina, losartan, atenolol, hidroclorotiazida, ácido acetilsalicílico, prednisona e metotrexato. Foi submetido à angioplastia em artéria renal esquerda, com colocação de stents sem intercorrências, com sucesso angiográfico e sem alterações da função renal. No retorno, estava assintomático e com bom controle da pressão, em uso de quatro medicamentos anti-hipertensivos, clopidogrel, azatioprina e prednisona. Ao exame físico, pressão arterial, aferida com paciente sentado, de 124x78 mmHg em ambos os membros superiores. 